ISSN 2413-0877 Volume 1 (2015)

The 1st International Symposium on Aquatic Product Processing 2013

\title{
USE OF FISH OIL AS SUPPLEMENT TO RICE FLOUR FOR CHILDREN
}

\author{
Ade Nugraheni*, Fifi Retiaty, Komari \\ Centre of Biomedical and Basic Technology of Health \\ *e-mail: nugraheniade@yahoo.com
}

\begin{abstract}
Fish oil is a source of omega 3 fatty acids, especially DHA and EPA having health benefits, such as prevention of heart disease and improvement of brain development including vision. However, these components are susceptible to oxidative damage and its fishy smell may affect consumer acceptance. This study aimed to immobilize this oil in rice flour usually prepared for "sumsum" porridge, a traditional meals for children or mother. Some of type of polymer are mixture with oil and was sprayed on to the rice flour to ensure the oils were coated with these polymer. Hedonic test of "sumsum" porridge was performed for acceptability for $4 \%$ fish oil and $4 \%$ equal weight of polymer malto-dextrin and soy flour. The nutrient contents were also presented. The nutrient content of the sample could be use as food supplement for under-five year children and his mother.
\end{abstract}

Keywords: fish oil, applement, omega 3 fatty acids

\section{INTRODUCTION}

Health Research Data (Riskesdas) in 2010 showed that the nutritional status and nutrient intake of Indonesian children are still problematic. One of the nutrient which play a role in the development of the child is an essential fatty acid which is composed of omega-3 fatty acids ( linolenic acid ), EPA and DHA. Essential fatty acids can not be made in the body, but must be obtained from food. When deficiency of essential fatty acids, the neuron cell will suffer from a lack of energy for the growth process so that the formation of the cell wall of neurons inhibited and cells are not able to hold a charge of neuron cell components normally.

Fish oil is one of source of omega-3 fatty acids, especially DHA and EPA. These fatty acids have proven benefits for the health, such as it can prevent of heart disease, to improve children's intelligence and children's vision. The main foods which contain of essential fatty acids are fish from the sea, such as salmon, tuna, mackerel, and tongkol. But the children usually be less like a fish dish. For that we need the food products fortified with omega- 3 essential fats.

The purpose of the research is to obtain "sumsum" porridge formula rich with omega 3 fatty acids.

\section{MATERIALS AND METHODS}

The making of "sumsum" porridge rich with omega-3 made of four formulations with the main ingredients composition of 150 grams of white rice flour, salt to taste, 4 cups of water, 3 tablespoons of full cream milk powder. Oven with a temperature of 150 degrees Celsius for 25 minutes. 


\section{The Making of Flour Fortification}

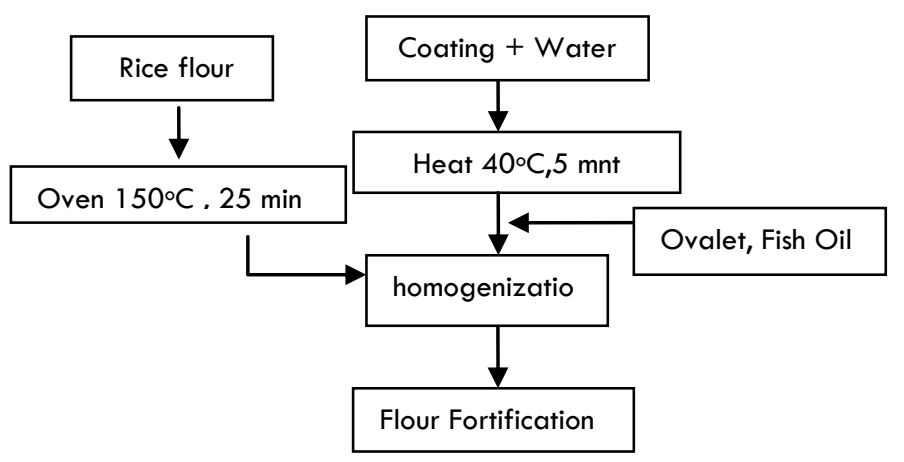

Figure 1. The process of making flour fortification

Parameters were observed in the "sumsum" porridge is water content, ash content, protein content, oil content, the amount of omega 3 and organoleptic tests. F1 formula is "sumsum" porridge without the addition of fish oil, F2 formula is "sumsum" porridge with the addition of fish oil (4\%) without the coating. F3 formula and F4 formula are "sumsum" porridge with the addition of fish oil (4\%) with coating in a row is maltodextrin $(4 \%)$ and $4 \%$ equal weight of polymer malto-dextrin and soy flour.

\section{The Making of "sumsum" porridge}

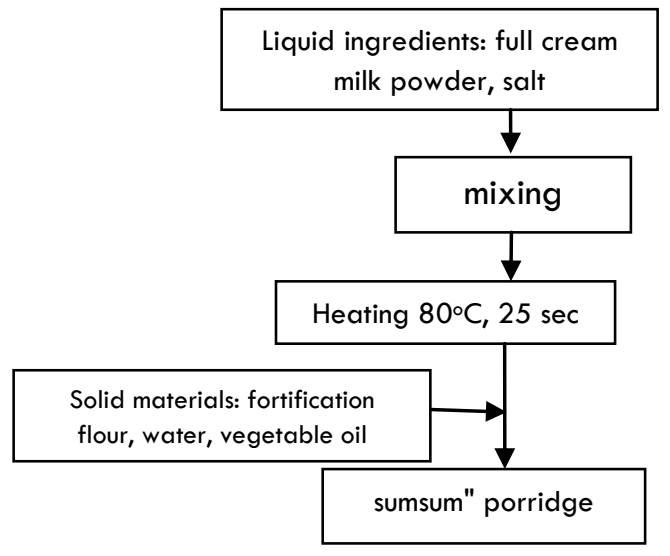

Figure 2. The Making of "Sumsum" Porridge

\section{Analysis of Omega 3 Fatty Acids}

3.1 Saponification fish oil

A total of 350 grams of purified fish oil saponified with 700 grams of $\mathrm{NaOH}$ solution in dilute alcohol (120 g NaOH and $1.25 \mathrm{~g}$ Ethylene diamine tetraacetic acid (EDTA) was dissolved in $400 \mathrm{ml}$ of distilled water and $400 \mathrm{ml}$ of ethanol $96 \%$ ). Saponification carried out at room temperature for 8 hours with constant stirring while gas flowed nirogen. The results of the saponification of $6 \mathrm{~N} \mathrm{HCl}$ was added to the solution until the $\mathrm{pH}$ reached 1. After the $\mathrm{pH}$ of 1 is reached, and then $\mathrm{n}$-hexane was added $200 \mathrm{ml}$ (several times). The mixture was evaporated with a rotary evaporator at a temperature of $30^{\circ} \mathrm{C}$. 


\subsection{Fractionation with urea}

A total of 25 grams of fatty acid saponification results above were added to a solution of urea in $100 \mathrm{ml}$ of hot $\left(65-70^{\circ} \mathrm{C}\right.$ ) (the ratio of urea / fatty acid at 4:1) and $267 \mathrm{ml}$ of methanol. The mixture was stirred until clear. Urea and urea complex compounds left overnight to crystallize at temperatures between $-36^{\circ} \mathrm{C}$ to $36^{\circ} \mathrm{C}$. After filtration, the liquid phase is evaporated vacuum at room temperature. The concentrate was added with $125 \mathrm{ml}$ of $\mathrm{HCl} \mathrm{0,1}$ $\mathrm{N}$ and $125 \mathrm{ml} \mathrm{n}$-hexane. Then the hexane layer was separated. The bottom of layer was extracted again with $50 \mathrm{ml}$ of $\mathrm{n}$-hexane. The mixture of hexane was vacuum evaporated phase at room temperature. Concentrates which obtained added by octyl gallate as a stabilizer. Concentrate which obtained was concentrated omega- 3 fatty acids rich with EPA and DHA.

\section{RESULT AND DISCUSSION}

Table 1. The proximate composition of flour

\begin{tabular}{lllll}
\hline & \multicolumn{4}{c}{ Formula } \\
\cline { 2 - 5 } Component (\%) & $\mathrm{F} 1$ & $\mathrm{~F} 2$ & $\mathrm{~F} 3$ & $\mathrm{~F} 4$ \\
\hline 1. Moisture & 10,30 & 14,07 & 12,32 & 11,04 \\
2. Ash & 0,49 & 0,52 & 0,66 & 0,61 \\
3. Fat & 0,07 & 1,54 & 1,29 & 1,60 \\
4. ALA & 0,004 & 0,04 & 0,08 & 0,09 \\
5. EPA & 0,030 & 0,36 & 0,61 & 0,73 \\
6. DHA & 0,025 & 0,27 & 0,54 & 0,63
\end{tabular}

Note: $\quad F 1=$ without oil, F2 = oil without coating, F3 = oil with maltodextrin coating, F4 = oil with maltodextrin coating and ISP

1. Omega 3 levels

The addition of omega- 3 fatty acids intended to add value of sum-sum porridge because omega- 3 fatty acids are believed to increase the intelligence of the brain, especially for the children, while the adults are expected to help lower cholesterol levels and help to prevent coronary heart disease. To be able to determine the quality of fortified formula results, it is necessary to do a comparison between the characteristics before and after fish oil formulated. Fish oil will be isolated to obtain omega - 3 fatty acids is fish oil that has been through the process of separation and purification method (Medina et al, 1995) . Isolation procedure is divided into two stages, namely saponification and fractionation.

The low concentrations of omega-3 fatty acids assumed because the damage of the double bond due to the relatively high temperatures in the heating process and by the oxidation reaction. From the four formulas, the highest of omega-3 fatty acid levels are called F4 formula. It's rice flour which has given by fish oil with coating maltodextrin and soy flour, after that following by the F3 formula rice flour which has given fish oil with coating maltodextrin rice flour, while F3 formula is rice flour which has given by fish oil had higher levels of omega- 3 under F3. For F1 formula is rice flour without oil had the lowest levels of 
omega-3 fatty acids are the lowest. Formula F3 and F4 which attended to have higher levels of omega 3 fatty acids because of the coating that is used on fish oil before it is sprayed on rice flour. According to Apriyantono, ( 2011), to avoid the damage because the oxidation of the omega- 3 fatty acids are usually encapsulated (coated) which is in this case omega- 3 fatty acids will be inside a coating (enkapsulan). From Figure 3 it can be seen that the amount of omega - 3 formula F3 and F4 higher than the formula F2 as a result of the addition of the coating material is sprayed on the oil before the flour. Levels of omega- 3 with a mixture coating of maltodextrin with soy flour higher than the maltodextrin coating. The combination of protein and carbohydrates as coating agent is more advantageous because it can increase the stability of the oil against oxidative damage (Ono and Aoyama, 1979). Besides that the addition of soy flour in coating ingredients of maltodextrin causing the total oil in the flour becomes higher. Levels of omega-3 fatty acids of F2 formula is lower than the

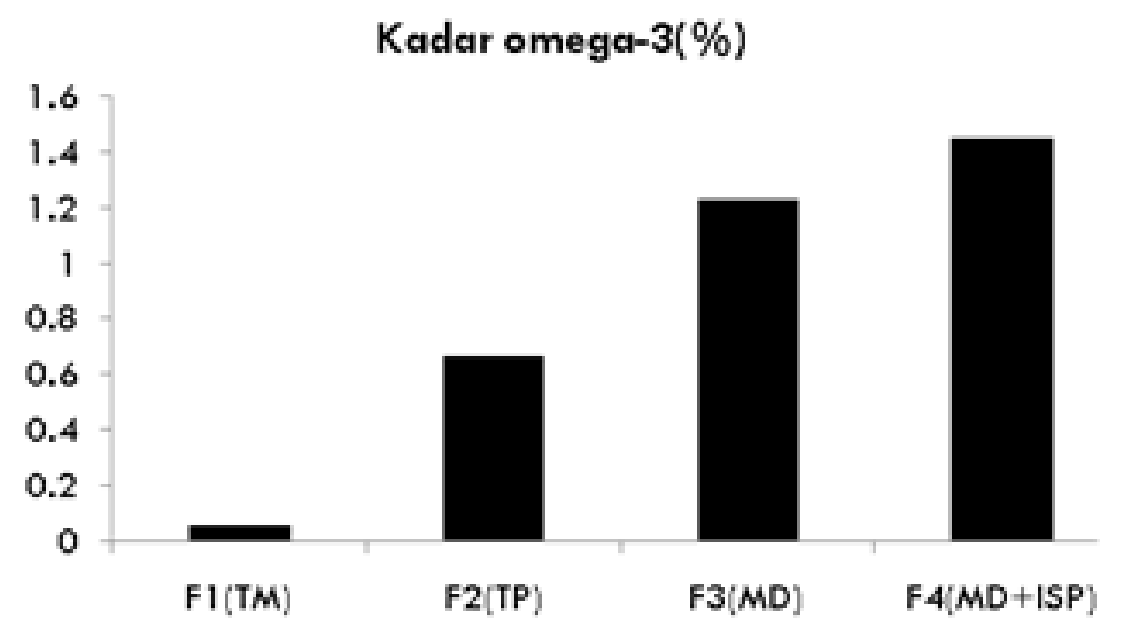

Fig 3. . Effect of formulation on levels of omega-3

F3 formula, this is due to the fish oil coating is not done when sprayed onto the rice flour .

From the results of measurements of the amount of omega- 3 turns on very small flour ranged between $0.059 \%$ to $1: 45 \%$. After analyzing t-test has seen that there are real differences in the levels of omega-3 in the fourth formulation (0.05).

2. The assessment of "sumsum"porridge's hedonic test

Based on the analysis of variance $(\alpha=0.05)$ showed that the treatment accorded to the four formulations did not significantly affect to the flavour, color, and texture of "sumsum" porridge. However, the effect on the taste of "sumsum" porridge. From the four formulas, panelists tend to like the $\mathrm{F} 4$ formula is the addition of fish oil $(4 \%)$ with coating in a row is maltodextrin $(4 \%)$ and $4 \%$ equal weight of polymer malto-dextrin and soy flour. Panelist acceptance on the aroma, texture, color and flavor can be seen in Figure 4. 


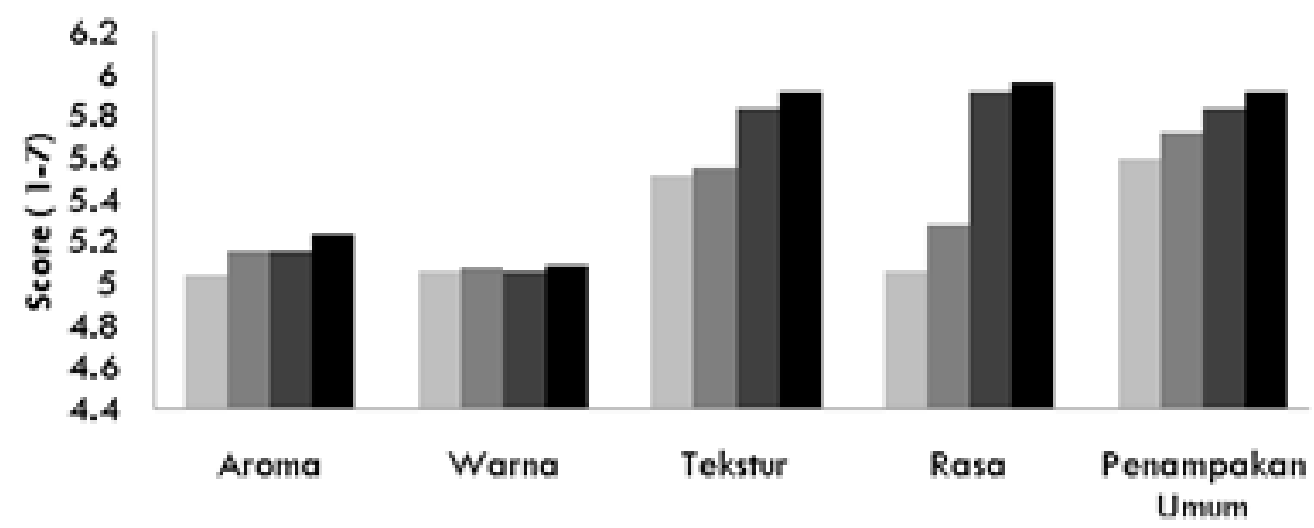

Fig 4. The formulation of the influence

\section{CONCLUSION}

Results of analysis of variance $(\alpha=0.05)$ showed that the addition of fish oil as much as $4 \%$ in the fourth formulation gives a noticeable effect on the levels of omega- 3 fatty acids and flavor of "sumsum"porridge but does not significantly affect the aroma, color, and texture of "sumsum"porridge. From the four formulas, panelists tend to like the F4 formula which addition of $4 \%$ fish oil with a combination of maltodextrin coating and soy protein isolate $(1: 1)$ in the "sumsum"porridge.

\section{REFERENCES}

Apriyantono,A.201 1. Titik kritis Kehalalan Susu cair dan SusuBubuk. https://www.facebook.com/notes/komunitas (Desember 2011).

Horwitz, W(ed). 2005. Official Methods of Analysis of AOAC International Maryland : AOAC International.

Medina, A. R., A. G. Gimenez, F. G. Camacho, J.A. S. Perez, E. M. Grima, and A.C. Gomez. 1995. Con-centration and Purification of Stearidonic, Eicosapentaenoic, and Docosahexaenoic Acids from Cod Liver Oil and the Marine Microalga Isochrysis galbana. J. of the American Oil Chem. Soc. 72 (5): 575 -583 .

Ono,F. dan Y.Aoyama. 1979. Encapsulation and stabilization of oily substances by protein and carbohydrate. J. Jpn. Soc. Food Sci. Tech.26:13-17 